\title{
Editorial
}

\section{Introduction to the first issue of International Journal of Otorhinolaryngology and Head and Neck Surgery}

\author{
Jyoti P. Dabholkar* \\ Department of ENT and Head and Neck Surgery, KEM Hospital, Mumbai, Maharashtra, India \\ *Correspondence: \\ Dr. Jyoti P. Dabholkar, \\ E-mail: drjpdabholkar@gmail.com \\ Copyright: (C) the author(s), publisher and licensee Medip Academy. This is an open-access article distributed under \\ the terms of the Creative Commons Attribution Non-Commercial License, which permits unrestricted non-commercial \\ use, distribution, and reproduction in any medium, provided the original work is properly cited.
}

In the recent times, great developments have taken place in the field of otorhinolaryngology and head and neck surgery. Modern ossicular prosthesis, middle ear implants, cochlear implants and BAHA have given a solution to hearing loss especially sensori-neural hearing loss. The sinus endoscope has gone beyond the confines of paranasal sinuses and has made visualisation of anterior skull base surgery possible. Thus enabling ENT surgeon to operate pituitary tumour and aggressive benign tumours like angiofibroma with intracranial extent.

Head and neck surgery is a happening field and I have seen many youngsters wanting to take this field. Transoral laser surgery via microlaryngoscopy and transoral robotic surgery have evolved and day is not so far when robotic surgery will be available at many centers. With advent of recent advanced radiation techniques like IMRT, IGRT and bio-radiation, laryngeal preservation is possible today.

In arena of research, molecular markers and personalized medicine, whereby treatment can be tailored according to patient's genetic makeup, is farfetched dream but I am sure that will be available soon.

Research and dissipation of attained knowledge is the keystone for progress and better future. With these goals in mind, I feel elated to release the first issue of our journal "International Journal of Otorhinolaryngology and Head and Neck Surgery". Our aim is to provide a platform for researchers and clinicians to present their work and help them to share their knowledge across the globe. We also want to encourage the young minds to publish their projects and dissertations. Our journal is an international, indexed and peer reviewed journal. We have resorted to open access policy for the benefits of users and readers.

The success of any journal is by contribution of colleagues and experts, so kindly give constant support and feedback to improve it's quality.

Cite this article as: Dabholkar JP. Introduction to the first issue of International Journal of Otorhinolaryngology and Head and Neck Surgery. Int J Otorhinolaryngol Head Neck Surg 2015;1:1. 